\title{
Neue Medien und alte Rituale in Todesnähe
}

\author{
Anita Lanz \\ Pflegefachfrau IPS-Onkologie-Anästhesie, Palliative Care
}

Die digitale Welt nimmt immer mehr Platz in unserem Alltag ein. Für uns, die der älteren Generation angehören, bedeutet dies ein Umdenken und ein Loslassen von Altem und Gewohntem. Wir verbinden den Tod und das Abschiednehmen eher mit Seelsorgern, Kirche, Ritualen und klassischer Beerdigung auf dem

Die Möglichkeit, sich ein letztes Mal in die Augen zu schauen, ist sowohl für den Sterbenden wie auch für die Angehörigen ein grosser Trost.

Friedhof als mit Handys oder Tablets. Für diejenigen, die sich fern des Geschehens aufhalten, sind die neuen Medien wie Face-Time oder Skype eine Option, an diesen emotional einschneidenden Ereignissen teilzunehmen.

Diese Möglichkeit, sich ein letztes Mal in die Augen zu schauen, ein Wort der Zuneigung zu äussern, um Verzeihung zu bitten oder nur Adieu sagen zu können, ist sowohl für den Sterbenden wie auch für die Angehöri- gen ein grosser Trost in einem Moment der Verzweiflung und Trauer. Da im Trauerprozess oft Schuldgefühle auftreten, kann die Erinnerung an diesen letzten Moment möglicherweise zur Linderung des Abschiedsschmerzes beitragen.

Können wir in diesem Spannungsfeld einen Mittelweg finden und die neuen Medien in Todesnähe ohne ethische Bedenken nützen? Möglichkeiten, miteinander über weite Distanzen zu reden und auch visuell kommunizieren zu können, stehen heute vielen Menschen offen, vorausgesetzt, sie sind bereit, diese zu nutzen.

\section{Fallbeispiel Oskar}

Als ehemalige Palliativschwester im Ruhestand erreicht mich ab und zu der Wunsch einer Familie, ihr im Sterbeprozess ihrer Angehörigen beizustehen.

So rief mich eines Abends eine Hausärztin an und bat mich, sie zu einem uns beiden bekannten Patienten (Oskar) zu begleiten. Wir besuchen Oskar, der an einem

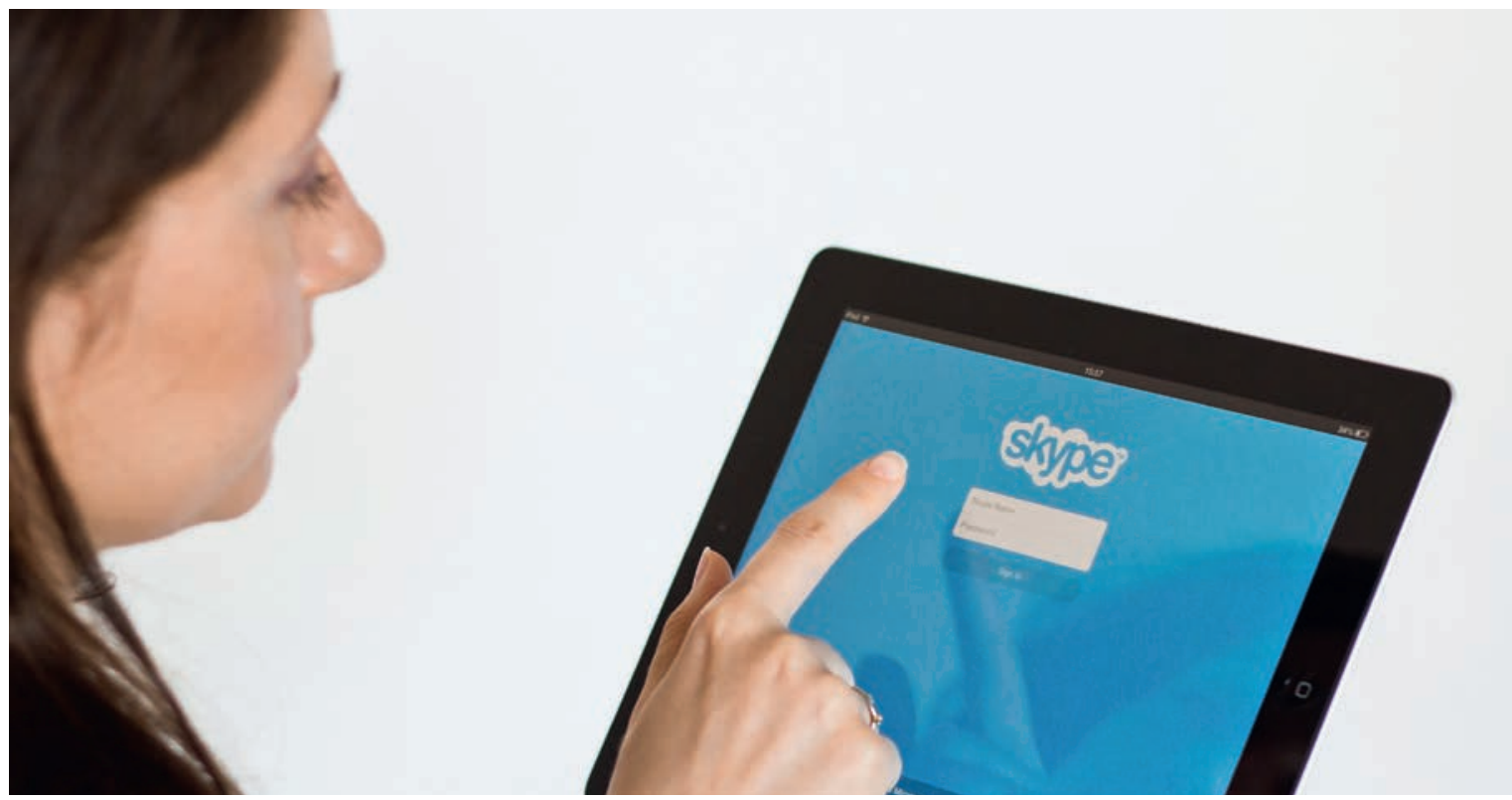

Im ersten Moment scheinen das Abschiednehmen von einem geliebten Menschen und die Nutzung neuer Medien nicht zusammenzupassen. Doch wenn die Zeit für eine Heimreise nicht mehr reicht, bietet das Telefonieren via Skype oder Face-Time die Möglichkeit, sich noch einmal zu sehen und voneinander zu verabschieden. 
unbehandelten metastasierenden Pankreaskarzinom leidet. Er wirkt müde, verneint Schmerzen, klagt aber über Übelkeit und Erbrechen. Wir besprechen gemeinsam die pflegerischen und medizinischen Massnahmen und das weitere Vorgehen.

Am nächsten Tag besuche ich Oskar wieder. Er sitzt am Tisch, und wir beginnen uns über seine Situation zu unterhalten. Auf die Frage, ob er Ziele habe, die er noch erreichen möchte, antwortet er: «Nein.» Auch nicht,

\section{Skype- und Face-Time-Anrufe bleiben die einzigen Möglichkeiten, den Sohn in die Gemeinschaft der Familie einzubinden.}

mit der Familie Weihnachten zu feiern? «Nein», entgegnet er, «ich habe abgeschlossen und werde bald sterben. Wichtig ist mir, zu Hause sterben zu dürfen und bei meiner Familie zu sein.»

Wir schweigen, und intuitiv ahnen wir vermutlich beide, dass das sehr bald sein wird. Die bestehenden Symptome sind unter Kontrolle, aber Oskar verweigert vehement das Essen und Trinken.

Am Abend vereinbare ich zusammen mit der Hausärztin einen weiteren Besuch. Als wir ankommen, liegt Oskar schlafend auf dem Sofa. Seine Rasselatmung ist das Erste, was unsere Aufmerksamkeit weckt. Oskar ist kaum mehr weckbar, und die Zeichen seines nahenden Todes sind klar sichtbar. Die Hausärztin verordnet die nötigen Medikamente, um Oskars Symptome zu lindern. Die Spitexpflegefrau teilt uns mit, dass ein Pflegebett auf dem Weg zum Patienten sei.

Da sich der Sohn der Familie im Ausland befindet, besprechen wir, wie wir die Situation angesichts des dramatisch und sich überraschend schnell verschlechternden Zustands von Oskar handhaben sollen. Oskars Wunsch, die Familie bei sich zu haben, liegt uns allen sehr am Herzen. Skype- und Face-Time-Anrufe bleiben die einzigen Möglichkeiten, den Sohn in die Gemeinschaft der Familie einzubinden. Für eine Heimreise reicht die Zeit nicht mehr. Da ein Seelsorger erwünscht ist, biete ich der Familie an, den Pfarrer zu organisieren. Wir verlassen alle das Haus, nur Ehefrau und Tochter bleiben alleine bei Oskar. Mit dem Seelsorger vereinbare ich später am Abend einen gemeinsamen Besuch.

Kaum zu Hause angekommen, klingelt mein Telefon. Da Oskar kaum mehr atmet, bittet mich die Familie, sofort zu kommen. Bei meiner Ankunft ist Oskar schon gestorben - gerade in dem Moment, als Ehefrau und Tochter mit dem Sohn im Ausland telefonierten.

Oskars Wunsch, bis zuletzt in der Gemeinschaft seiner Familie sein zu können, wurde ihm erfüllt. Für den Sohn brachte die Möglichkeit, von diesem Moment am Sterbebett nicht ausgeschlossen zu sein und sich verabschieden zu können, sicher ein wenig Trost beim Verlust des Vaters.

\section{Oskars Wunsch, bis zuletzt in der Gemeinschaft} seiner Familie sein zu können, wurde ihm erfüllt.

Diese Erfahrung zeigt, wie nützlich und bereichernd die Verwendung der neuen Medien für die Beteiligten, auch in Todesnähe, sein kann. Seien wir dankbar für die neuen Möglichkeiten.

Bildnachweis

() Viorel Dudau | Dreamstime.com 